\title{
A double-blind randomized controlled trial comparing dexamethasone and clonidine as adjuvants to a ropivacaine sciatic popliteal block for foot surgery
}

\author{
This article was published in the following Dove Press journal: \\ Local and Regional Anesthesia \\ 5 May 2016 \\ Number of times this article has been viewed
}

\author{
Kris Vermeylen' \\ Joris De Puydt ${ }^{2}$ \\ Stefan Engelen ${ }^{3}$ \\ Eva Roofthooft ${ }^{3}$ \\ Filiep Soetens' \\ Arne Neyrinck ${ }^{4}$ \\ Marc Van de Velde ${ }^{4}$ \\ 'Department of Anesthesia and \\ Intensive Care, AZ Turnhout, \\ Turnhout, ${ }^{2}$ Department of Anesthesia, \\ University Hospital Antwerp, Antwerp, \\ ${ }^{3}$ Department of Anesthesia, ZNA \\ Hospital Network Antwerp, Antwerp, \\ ${ }^{4}$ Department of Cardiovascular \\ Sciences and Anesthesiology, Catholic \\ University Hospitals, Louvain, Belgium
}

Correspondence: Kris Vermeylen Department of Anesthesia and Intensive Care, AZ Turnhout, Steenweg op Merksplas I44, 2300 Turnhout, Belgium Tel +3247765 5065

Email kris.vermeylen@gmail.com
Background and aims: A popliteal block is effective in managing postoperative pain for foot surgery, but since the duration of analgesia is limited following a single-shot popliteal fossa block technique, methods to prolong effective postoperative analgesia are mandatory. The aim of this study was to assess the effect of adjuvants to ropivacaine on the duration of sensory and motor block.

Methods: In this double-blind randomized placebo-controlled study, we evaluated the analgesic effect of clonidine or dexamethasone (DXM) when added to ropivacaine for hallux valgus surgery. After obtaining institutional ethics research board approval and written informed consent, a total of 72 patients were randomly allocated. Fifty-seven of these patients were statistically analyzed. All patients received an ultrasound-guided single-shot popliteal fossa block with $30 \mathrm{~mL}$ of ropivacaine $0.75 \%$, supplemented with saline, clonidine $100 \mu \mathrm{g}$, or DXM $5 \mathrm{mg}$. The primary end point was time to first pain sensation. Secondary end points were time to complete sensory and motor block regression.

Results: Compared to saline, duration to first pain sensation was prolonged by 9 hours (mean \pm standard deviation: $31 \pm 9$ hours) $(42 \%)$ in the DXM group $(P=0.024)$ and by 6 hours ( $28 \pm 10$ hours) $(27 \%)$ in the clonidine group $(P=0.024)$. Compared to saline, DXM prolonged both complete sensory and motor blockade by 12 hours ( $25 \pm 7$ hours) $(46 \%)$ and 13 hours ( $36 \pm 6$ hours) $(55 \%)$, respectively, while clonidine prolonged complete sensory and motor blockade by 7 hours (30 \pm 7 hours) (27\%) and 2 hours ( $22 \pm 5$ hours) (10\%), respectively. DXM prolonged sensory block regression time by 6 hours ( $21 \pm 7$ hours) (41\%) and clonidine by 2 hours (17 \pm 6 hours) (13\%) compared to the control group $(P=0.006)$. Similarly, DXM prolonged motor block regression by 7 hours $(25 \pm 7$ hours) $(46 \%)$ and clonidine by 4 hours $(21 \pm 4$ hours $)(19 \%)(P<0.0001)$.

Conclusion: Addition of DXM and clonidine to ropivacaine significantly prolonged the duration of postoperative sensory and motor block.

Keywords: popliteal block, hallux valgus, steroids, regional anesthesia, dexamethasone, clonidine

\section{Introduction}

Foot surgery is associated with severe pain that can extend significantly up to 48 hours and often requires large amounts of parenteral opioids. ${ }^{1,2}$ Sciatic nerve blockade reduces postoperative pain after major foot and ankle surgery with minimal side effects; ${ }^{3}$ however, the maximum duration of effective analgesia with long-acting local anesthetics after a single injection technique is only $8-24$ hours. ${ }^{4}$ Therefore, perineural catheters 
or local anesthetics in combination with adjuvants are often used in attempts to prolong the duration of a single-shot popliteal fossa block (SSPFB). ${ }^{5,6}$ Pharmacodynamics and pharmacokinetics of dexamethasone (DXM) and clonidine administered in regional nerve blocks are not yet fully understood; however, quite some literature has been published concerning the prolonged effect of DXM and clonidine on block characteristics.

Clonidine is a frequently used additive to local anesthetics $^{7-9}$ and is used for neuraxial blocks (eg, caudal blocks in children ${ }^{10}$ ) and for peripheral nerve blocks. ${ }^{8}$ In particular, clonidine is known to prolong the duration of analgesia for brachial plexus and popliteal fossa blocks. ${ }^{11}$ However, some studies have reported no change in onset time or block duration. ${ }^{1-14}$ This lack of effect has been attributed to methodological issues, eg, difficulties in data interpretation, lack of systematic controls, or to the specific intermediate- and short-acting local anesthetics that were studied. ${ }^{7}$ Additionally, many studies were performed prior to the widespread use of ultrasound-guided nerve blockade, which may have limited the accuracy of local anesthetic delivery. ${ }^{1-3,18}$

DXM has also shown some promise as an adjuvant that prolongs analgesia in brachial plexus blocks. ${ }^{15-18}$ Recently, Cummings et $\mathrm{al}^{5}$ reported prolonged analgesia when DXM was combined with a long-acting local anesthetic during interscalene block. Desmet et al and Cummings et al found that DXM (8 $\mathrm{mg}$ ) as an adjuvant to ropivacaine or bupivacaine almost doubled block duration (up to 24 hours) when used as an additive for the interscalene block. ${ }^{5,18}$

In this double-blind randomized placebo-controlled study, we evaluated the addition of DXM or clonidine to an ultrasound-guided SSPFB with $30 \mathrm{~mL}$ of ropivacaine $0.75 \%$. The primary end point was time to first pain sensation visual analog scale ([VAS] score $>3$ ). We hypothesized that, compared to saline, DXM and clonidine prolong the time to first pain sensation.

\section{Methods}

\section{Population and study design}

This trial is registered at the Community Clinical Trial System (EudraCT number: 2012-005573-31). Hospital ethics committee approval (EC approval no 3734, Commissie voor Medische Ethiek - Ziekenhuisnetwerk Antwerpen, December 01, 2011) was received. All patients scheduled for elective foot surgery were screened. Exclusion criteria were refusal of the patient, protocol violations, Nonsteroidal anti-inflammatory drug (NSAID) intolerance, diabetic patients, allergy for local anesthetics, peripheral neuropathy, coagulation disorders, and patients with an impaired kidney function. Patients were asked to participate when no contraindications to study participation were identified. We asked 208 patients to give consent, but 57 refused. A total of 72 patients were randomly allocated by a computer-generated model to one of three study groups (clonidine, DXM, or saline). Fifty-seven of these patients were statistically analyzed (Figure 1). An SSPFB sciatic nerve block was performed 60 minutes before surgery, and block onset times were recorded.

\section{Procedure}

Following establishment of intravenous (IV) access, an ultrasound-guided SSPFB was performed with the patient in the prone position using the posterior approach. The probe was placed in the popliteal fossa (short axis view of the nerves) to detect the popliteal artery and vein, and the biceps femoris muscle. The tibial nerve was identified usually lateral and more superficial to the popliteal artery. Following visualization of these structures, the probe was moved proximally to search for the bifurcation of the tibial nerve with the common peroneal nerve (4-10 $\mathrm{cm}$ proximal to the popliteal crease). Correct needle placement was confirmed using a nerve stimulator. Muscle twitches of the foot (plantar flexion, dorsiflexion or inversion of the ankle) evoked at a current of $0.5 \mathrm{~mA}$ served as an indicator of correct needle placement. When motor stimulation was accomplished with $\leq 0.2 \mathrm{~mA}$, or excessive resistance (pressure) to injection was felt, the needle was repositioned.

Ropivacaine was the local anesthetic of choice because of its favorable clinical ${ }^{19,20}$ and toxicity profile. ${ }^{21}$ Of the available concentrations, the $0.75 \%$ concentration was selected based on previous studies. ${ }^{19,22}$ Ropivacaine $0.75 \%$ (30 mL) was mixed with either $1 \mathrm{~mL}$ of saline (control group), $1 \mathrm{~mL}$ of DXM ( $5 \mathrm{mg})$, or $1 \mathrm{~mL}$ of clonidine $(100 \mu \mathrm{g})$ according to randomized assignment that was prepared by the pharmacist and blinded to the blinded block performer. In total, $31 \mathrm{~mL}$ of local anesthetic mixture was injected.

"Donut" signs around the posterior tibial nerve and the common peroneal nerve indicated successful distribution of the study solution. Two anesthesiologists with extensive experience with the popliteal block performed all blocks.

A research assistant blinded to group allocation evaluated sensory and motor block every 5 minutes after injection until start of surgery and every 10 minutes after surgery until discharge from the postanesthesia care unit. Sensory block was tested using a big toe pinprick and rated as $2=$ normal, $1=$ loss of sensation to pinprick, or $0=$ loss of sensation to light touch. Motor block was tested and rated as $2=$ normal movement, $1=$ partial paresis of ankle or toe movement, or $0=$ absent 


\section{Flow diagram popliteal study}

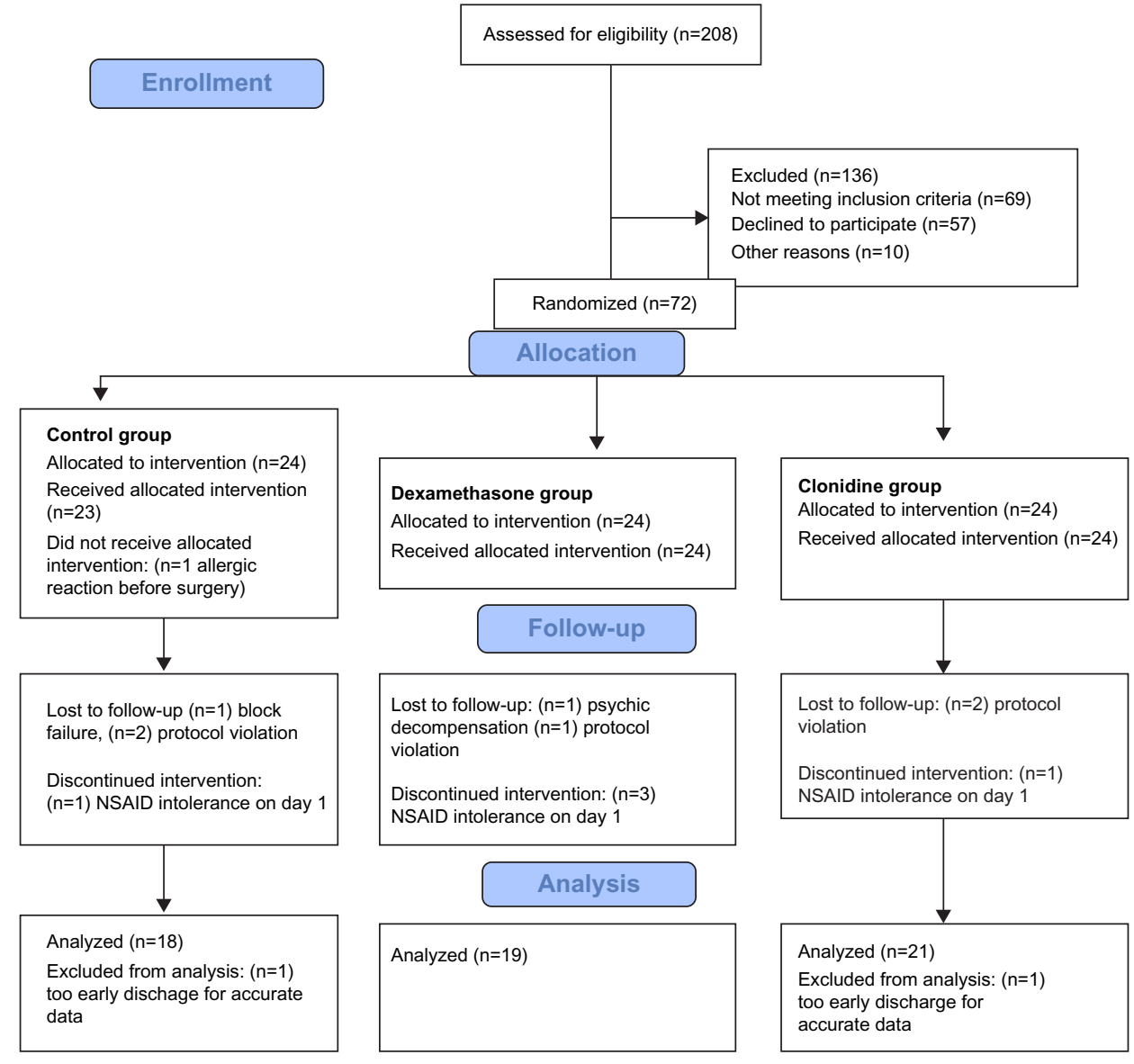

Figure I Flowchart of study patients.

Abbreviation: NSAID, nonsteroidal anti-inflammatory drug.

movement of the ankle and toes. Block success was defined as loss of sensation to pinprick (sensory score $\leq 1$ ) 45 minutes after injection of the local anesthetic mixture. Onset time was defined as the interval between the end of injection and loss of sensation to pinprick. ${ }^{23-28}$

All patients received general anesthesia induced with propofol $(2.5 \mathrm{mg} / \mathrm{kg})$ and sufentanil $(0.1 \mu \mathrm{g} / \mathrm{kg})$. A laryngeal mask airway was introduced following loss of consciousness. Sevoflurane 1-1.5 minimum alveolar concentration (MAC) was administered through a laryngeal mask airway to maintain anesthesia. Inspiratory oxygen fraction was $40 \%$. IV antibiotics were given before tourniquet insufflation. Standard anesthesia monitoring included pulse oximetry, capnography, noninvasive blood pressure, and a three-lead electrocardiogram. At the end of surgery, the tourniquet was deflated, and paracetamol $1 \mathrm{~g}$ was administered intravenously. Total tourniquet time was recorded from insufflation to deflation. No skin or wound traction was applied at the end of surgery. The same surgeon performed all interventions.
Paracetamol $1 \mathrm{~g}$ was administered every 6 hours, and ketorolac (Taradyl ${ }^{\circledR}$ ) $20 \mathrm{mg}$ was administered every 8 hours for the first 24 hours. The leg was elevated, and early postoperative mobilization was applied in the postanesthesia care unit and in the orthopedic ward.

After 24 hours, the analgesic regimen consisted of oral paracetamol $1 \mathrm{~g}$ qid and naproxen $550 \mathrm{mg}$ bid. Patients who developed stomachache on the first postoperative day were excluded from the study because NSAIDs were stopped and tramadol sublingual was then given to manage pain.

A blinded study nurse performed all postoperative recordings. The primary outcome variable was the time between start of block and the first pain reported by the patient. Patient-reported pain scores were recorded using the VAS ranging from 0 (no pain) to 10 (worst pain imaginable). Patients were considered to have pain if the VAS score exceeded 3. Sensory and motor block regression times were self-reported by the patients at different times. They were asked to report VAS scores every 2 hours 
Table I Age, tourniquet time, and onset times of 57 subjects undergoing popliteal blockade

\begin{tabular}{llllll}
\hline & All & Saline & Dexamethasone & Clonidine & P-value \\
\hline Age (years) & $48 \pm 15$ & $49 \pm 15$ & $48 \pm 15$ & $47 \pm 14$ & NS \\
Tourniquet time (minutes) & $39 \pm 11$ & $39 \pm 9$ & $42 \pm 14$ & $36 \pm 7$ & NS \\
Sensory onset time (minutes) & $28 \pm 35$ & $32 \pm 19$ & $34 \pm 42$ & $20 \pm 18$ & NS \\
Motor onset time (minutes) & $33 \pm 28$ & $33 \pm 20$ & $43 \pm 58$ & $24 \pm 18$ & NS \\
\hline
\end{tabular}

Note: Data is presented as mean \pm standard deviation.

Abbreviation: NS, nonsignificant.

until complete sensory and motor block regression and to report supplementary scores when VAS scores exceeded 3 out of 10. Complications such as sedation, nausea, vomiting, and itching were noted. Onset of sensory block regression was defined as the first moment any feeling returned in the toes, typically a tingling sensation; complete sensory regression was defined as the return of normal sensation to touch of the toes. Onset of motor block regression was the first time the patient was able to move toes, and complete motor regression was the subjective feeling of normal motor function of the lower leg. Patients were discharged after full recovery of sensory and motor block and with a VAS score of 3 or less. After discharge, they were asked to keep a diary of VAS scores for 2 days (at least four times a day).

\section{Statistical analysis}

Sample size calculations were performed, and 18 patients per group were deemed necessary to achieve a power of $90 \%$ with a significance level of 0.05 to detect a difference of 6 hours in postoperative analgesia with estimated group standard deviations of 4.5 hours. ${ }^{18,29}$ A two-sided Student's $t$-test was performed.

Block regression duration was modeled using KaplanMeier curves, and a log-rank survival analysis was used to evaluate the differences among the study groups. Differences in age, tourniquet time, and motor and sensory block onset times were evaluated by Kruskal-Wallis analysis.

$P$-values $<0.05$ were considered statistically significant. The Statistical Package for the Social Sciences (SPSS for Windows, version 17.0; SPSS Inc., Chicago, IL, USA) was used for these analyses.

\section{Results}

We screened 208 patients. Sixty-nine were excluded from participation and 57 refused to participate. Finally, 72 patients were enrolled, of whom 15 were excluded. In the control group, six people were excluded. One was excluded because of an allergic reaction to antibiotics prior to incision, one because of block failure, and one because of suspected NSAID intolerance on day 1 (gastric pain). In this group, there were two protocol violations on the surgical ward, and one patient was sent home early for adequate data assessment. In the DXM group, there were five excluded patients. One patient turned out to be mentally instable for adequate data assessment. There was one protocol violation and three suspected NSAID intolerance. In the clonidine group, four people were excluded, two due to protocol violations, one with suspected NSAID intolerance, and one due to early discharge.

The groups did not differ in age, tourniquet time, and block onset times (sensory or motor) as shown by KruskalWallis analysis (Table 1).

After obtaining institutional ethics research board approval and written informed consent from eligible patients, 57 American Society of Anesthesiologists classification 1 and 2 patients were studied. All participants were female and the groups did not differ in other demographic characteristics. Onset of sensory and motor block did not differ among groups (Tables 2 and 3).

Compared to saline, duration to first pain sensation was prolonged by 9 hours $(42 \%)$ with the addition of DXM $(P=0.024)$ and by 6 hours $(27 \%)$ with the addition of clonidine $(P=0.024)$. Compared to saline, DXM prolonged both com-

Table 2 Primary and secondary end point results of 57 subjects undergoing popliteal blockade

\begin{tabular}{lllll}
\hline Time to ... & Saline & Dexamethasone & Clonidine & $P$-value \\
\hline .. First pain sensation (hours) & $22 \pm 6$ & $31 \pm 9(+42 \%)$ & $28 \pm 10(+27 \%)$ & 0.024 \\
... First sensory regression (hours) & $15 \pm 15$ & $21 \pm 7(+41 \%)$ & $17 \pm 6(+13 \%)$ & 0.006 \\
... First motor regression (hours) & $17 \pm 4$ & $25 \pm 7(+46 \%)$ & $21 \pm 4(+19 \%)$ & $<0.00 \mathrm{I}$ \\
... Complete sensory regression (hours) & $23 \pm 5$ & $36 \pm 6(+55 \%)$ & $30 \pm 7(+27 \%)$ & $<0.00 \mathrm{I}$ \\
$\ldots$ Complete motor regression (hours) & $20 \pm 2$ & $32 \pm 7(+55 \%)$ & $22 \pm 5(+10 \%)$ & $<0.00 \mathrm{I}$ \\
\hline
\end{tabular}

Note: Data is presented as mean \pm standard deviation. 
Table 3 Pairwise analysis of block survival times

\begin{tabular}{|c|c|c|c|}
\hline$P$-value & $\begin{array}{l}\text { Saline vs } \\
\text { dexamethasone }\end{array}$ & $\begin{array}{l}\text { Saline vs } \\
\text { clonidine }\end{array}$ & $\begin{array}{l}\text { Dexamethasone vs } \\
\text { clonidine }\end{array}$ \\
\hline Time to first pain sensation & 0.004 & 0.089 & 0.684 \\
\hline First sensory regression & 0.001 & 0.432 & 0.067 \\
\hline First motor regression & $<0.001$ & 0.022 & 0.006 \\
\hline Complete sensory regression & $<0.001$ & 0.005 & 0.245 \\
\hline Complete motor regression & $<0.001$ & 0.389 & 0.002 \\
\hline
\end{tabular}

plete sensory and motor blockade by 12 and 13 hours (55\%), respectively, while clonidine prolonged complete sensory and motor blockade by 7 hours (27\%) and 2 hours (10\%), respectively (Figure $1 \mathrm{C}$ and D).

DXM prolonged sensory block regression time by 6 hours (41\%) and clonidine by 2 hours (13\%). Log-rank survival analysis showed that these findings are statistically significant $(P=0.006)$. Similarly, DXM prolonged motor block regression by 7 hours (46\%) and clonidine by 4 hours $(19 \%)(P<0.0001)$. No significant side effects were recorded (Figure 2).

\section{Discussion}

Corticosteroids have a long history of use in neuraxial blocks and chronic pain treatment, for instance, in carpal tunnel syndrome, and they are acknowledged to be an effective and safe therapy. ${ }^{30}$ Desmet et $a 1^{18}$ and Cummings et al ${ }^{5}$ have found no evidence that the off-label use of perineural DXM is harmful. When studying the effect of ropivacaine and different adjuvants on isolated sensory neuron cell bodies of rats, Williams et $\mathrm{al}^{31,32}$ found that, unlike ropivacaine,
DXM did not increase cell death after 24 hours of exposure. Moreover, Ma et $\mathrm{al}^{33}$ reported a protective effect for DXM on bupivacaine-induced neuronal injury in rats. Thus, the short-term use of DXM appears to be safe ${ }^{34}$ and without risk for steroid-induced hyperglycemia. ${ }^{35}$

The perineural use of DXM has been widely published. ${ }^{31}$ Both Cummings et $\mathrm{al}^{18}$ and Desmet et $\mathrm{al}^{5}$ found that when DXM was added to an interscalene block, DXM prolonged the interscalene nerve block nearly twofold. These authors used 8 and $10 \mathrm{mg}$ DXM, while we used only $5 \mathrm{mg}$. This perhaps explains why in the present study the effect of DXM was less pronounced and a dose-response effect might occur. However, alternatively in the present study for the first time, DXM was added to a popliteal block, which also might explain the different results. Further difference between the present study and those of Cummings et al and Desmet et al is that we used ultrasound guidance to place the block.

Although the pharmacodynamics and pharmacokinetics of DXM and clonidine administered in regional nerve blocks are not yet fully understood, there is increasing
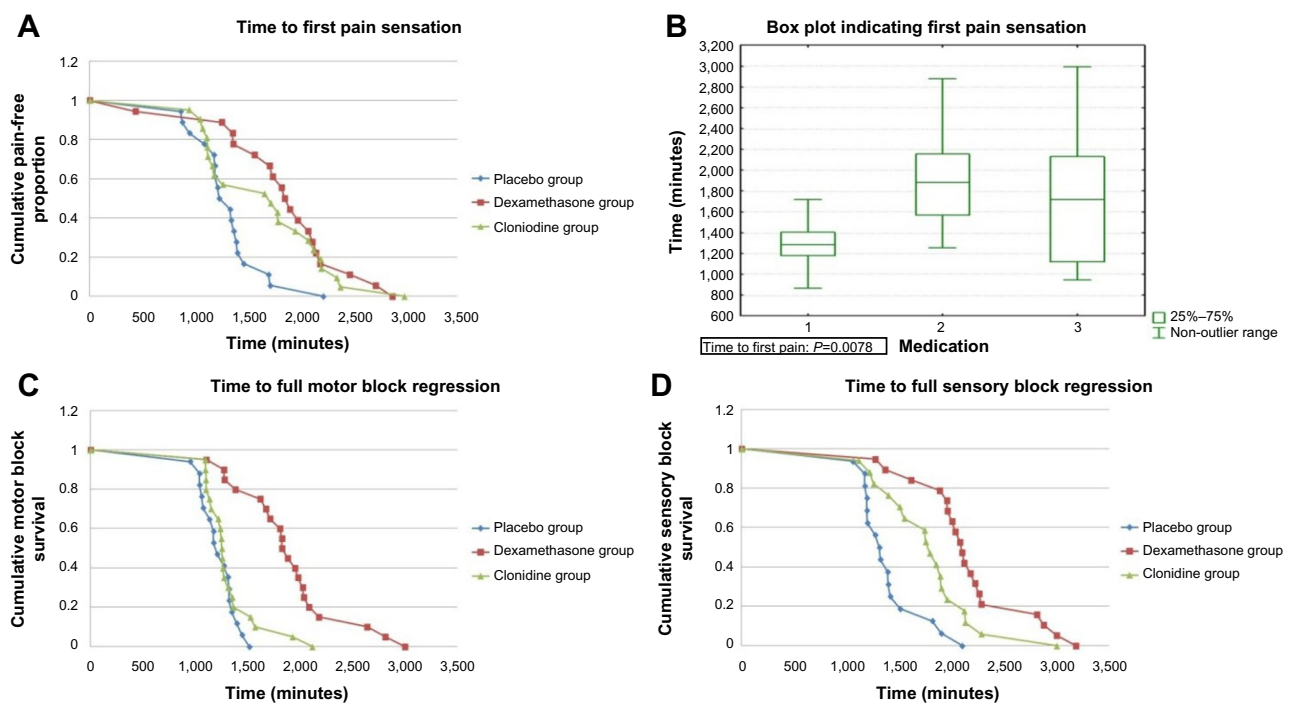

Figure 2 Block survival times.

Notes: (A) Kaplan-Meier (K-M) cumulative distribution for pain >3, (B) Box-whisker plot for pain-free intervals. K-M cumulative distribution for motor (C) and sensory (D) block duration. 
evidence that DXM prolongs the duration of postoperative analgesia. ${ }^{5,18,36}$

Desmet et $\mathrm{al}^{18}$ also had an IV DXM group and concluded that IV DXM is as good as perineural DXM in terms of pain relief. It was previously already demonstrated that systemic steroids improve postoperative pain sensation and reduce postoperative nausea and vomiting. ${ }^{37-39}$ Several hypotheses have been proposed to explain the analgesic effect of DXM. Steroids may induce vasoconstriction, leading to substantial reduction in the absorption of local anesthetic solution. ${ }^{15,40,41}$ Alternatively, DXM might block nociceptive impulse transmission along unmyelinated C-fibers through its anti-inflammatory and/or immunosuppressive effect. ${ }^{5,42-44}$ After intracellular uptake, glucocorticoids activate cytoplasmatic receptors that bind to their response elements in DNA. This decreases the production of inflammatory proteins (eg, cyclooxygenase-2, inducible nitric oxide synthase, cytoplasmatic phospholipase A2, interleukins, and inflammatory chemokines) and increases the production of anti-inflammatory proteins (lipocortin-1 receptor antagonist). ${ }^{18,45}$

Although clonidine is the most frequently used perineural additive to local anesthetics, ${ }^{46,47}$ its role as adjuvant in peripheral nerve blocks remains controversial, and side effects seem to increase at doses above $150 \mu \mathrm{g} .{ }^{46} \mathrm{YaDeau}_{\mathrm{et}} \mathrm{al}^{7}$ showed that a popliteal nerve block duration was prolonged when $100 \mu \mathrm{g}$ of clonidine was added to bupivacaine. Nonetheless, the peripheral analgesic effect of clonidine remains unclear, and further investigation examining the mechanisms of action is required.

The present study has significant limitations. Since we did not use IV patient-controlled analgesia morphine as rescue analgesia, we could not conclude that opioid sparing occurs with DXM or clonidine. However, to our knowledge, this is the first study to look at not only the analgesic effect but also in combination with sensory and motor block characteristics. Furthermore, we used a relatively large amount of local anesthetic volume $(30 \mathrm{~mL})$. It can be argued that given the fact that ultrasound was used for block placement, lower volumes should have been injected. However, since previous studies used high volumes, we decided to use similar volumes in the present study. Further study is required to evaluate if DXM can effectively reduce the dose of local anesthetic without affecting the duration of analgesia.

\section{Conclusion}

Our results demonstrate that adjuvants with ropivacaine $0.75 \%$ prolong the duration of an SSPFB. This is the first study to use a limited dose (5 mg) of DXM for SSPFB.
Perineural clonidine (limited to $100 \mu \mathrm{g}$ ) also prolonged block duration but to a lesser extent than DXM. Future dose-response studies are needed to evaluate if the positive effects of DXM are also present in lower doses. Additionally, neuronal toxicity of DXM and its effects on glucose metabolism need further study. Furthermore, combining clonidine and DXM might produce additive or synergistic effects.

\section{Author contributions}

Van de Velde and Hadzic contributed to the conception and design of this study. Data collection was done by Engelen and Roofthooft. Vermeylen mainly did the writing of the article, but the critical evaluation and final approval were done by all co-authors, in particular, Van de Velde. De Puydt performed the statistical analysis. All authors contributed toward data analysis, drafting and critically revising the paper and agree to be accountable for all aspects of the work.

\section{Disclosure}

The authors report no conflicts of interest in this work.

\section{References}

1. Ong CK, Lirk P, Seymour RA, Jenkins BJ. The efficacy of preemptive analgesia for acute postoperative pain management: a meta-analysis. Anesth Analg. 2005;100(3):757-773. [table of contents].

2. Needoff M, Radford P, Costigan P. Local anesthesia for postoperative pain relief after foot surgery: a prospective clinical trial. Foot Ankle Int. 1995;16(1):11-13.

3. di Benedetto P, Casati A, Bertini L, Fanelli G, Chelly JE. Postoperative analgesia with continuous sciatic nerve block after foot surgery: a prospective, randomized comparison between the popliteal and subgluteal approaches. Anesth Analg. 2002;94(4):996-1000. [table of contents].

4. Cappelleri G, Aldegheri G, Ruggieri F, Mamo D, Fanelli G, Casati A. Minimum effective anesthetic concentration (MEAC) for sciatic nerve block: subgluteus and popliteal approaches. Can J Anaesth. 2007;54(4):283-289.

5. Cummings KC 3rd, Napierkowski DE, Parra-Sanchez I, et al. Effect of dexamethasone on the duration of interscalene nerve blocks with ropivacaine or bupivacaine. Br J Anaesth. 2011;107(3):446-453.

6. Paqueron X, Narchi P, Mazoit JX, Singelyn F, Benichou A, Macaire P. A randomized, observer-blinded determination of the median effective volume of local anesthetic required to anesthetize the sciatic nerve in the popliteal fossa for stimulating and nonstimulating perineural catheters. Reg Anesth Pain Med. 2009;34(4):290-295.

7. YaDeau JT, LaSala VR, Paroli L, et al. Clonidine and analgesic duration after popliteal fossa nerve blockade: randomized, double-blind, placebo-controlled study. Anesth Analg. 2008;106(6):1916-1920.

8. Casati A, Magistris L, Fanelli G, et al. Small-dose clonidine prolongs postoperative analgesia after sciatic-femoral nerve block with $0.75 \%$ ropivacaine for foot surgery. Anesth Analg. 2000;91(2):388-392.

9. Casati A, Vinciguerra F, Cappelleri G, et al. Adding clonidine to the induction bolus and postoperative infusion during continuous femoral nerve block delays recovery of motor function after total knee arthroplasty. Anesth Analg. 2005;100(3):866-872. [table of contents].

10. Constant I, Gall O, Gouyet L, Chauvin M, Murat I. Addition of clonidine or fentanyl to local anaesthetics prolongs the duration of surgical analgesia after single shot caudal block in children. Br J Anaesth. 1998;80(3):294-298. 
11. Bernard JM, Macaire P. Dose-range effects of clonidine added to lidocaine for brachial plexus block. Anesthesiology. 1997;87(2):277-284.

12. Duma A, Urbanek B, Sitzwohl C, Kreiger A, Zimpfer M, Kapral S. Clonidine as an adjuvant to local anaesthetic axillary brachial plexus block: a randomized, controlled study. Br J Anaesth. 2005;94(1): $112-116$.

13. Culebras X, Van Gessel E, Hoffmeyer P, Gamulin Z. Clonidine combined with a long acting local anesthetic does not prolong postoperative analgesia after brachial plexus block but does induce hemodynamic changes. Anesth Analg. 2001;92(1):199-204.

14. Murphy DB, McCartney CJ, Chan VW. Novel analgesic adjuncts for brachial plexus block: a systematic review. Anesth Analg. 2000; 90(5):1122-1128.

15. Movafegh A, Razazian M, Hajimaohamadi F, Meysamie A. Dexamethasone added to lidocaine prolongs axillary brachial plexus blockade Anesth Analg. 2006;102(1):263-267.

16. Parrington SJ, O'Donnell D, Chan VW, et al. Dexamethasone added to mepivacaine prolongs the duration of analgesia after supraclavicular brachial plexus blockade. Reg Anesth Pain Med. 2010;35(5):422-426.

17. Shrestha BR, Maharjan SK, Tabedar S. Supraclavicular brachia plexus block with and without dexamethasone - a comparative study. Kathmandu Univ Med J (KUMJ). 2003;1(3):158-160.

18. Desmet M, Braems H, Reynvoet M, et al. I.V. and perineural dexamethasone are equivalent in increasing the analgesic duration of a single-shot interscalene block with ropivacaine for shoulder surgery: a prospective, randomized, placebo-controlled study. $\mathrm{Br} J$ Anaesth. 2013;111(3):445-452.

19. Casati A, Fanelli G, Borghi B, Torri G. Ropivacaine or $2 \%$ mepivacaine for lower limb peripheral nerve blocks. Study Group on Orthopedic Anesthesia of the Italian Society of Anesthesia, Analgesia, and Intensive Care. Anesthesiology. 1999;90(4):1047-1052.

20. Fanelli G, Casati A, Beccaria P, et al. A double-blind comparison of ropivacaine, bupivacaine, and mepivacaine during sciatic and femoral nerve blockade. Anesth Analg. 1998;87(3):597-600.

21. Dony P, Dewinde V, Vanderick B, et al. The comparative toxicity of ropivacaine and bupivacaine at equipotent doses in rats. Anesth Analg. 2000;91(6):1489-1492.

22. Casati A, Fanelli G, Cappelleri G, et al. A clinical comparison of ropivacaine $0.75 \%$, ropivacaine $1 \%$ or bupivacaine $0.5 \%$ for interscalene brachial plexus anaesthesia. Eur J Anaesthesiol. 1999;16(11): 784-789.

23. Buys MJ, Arndt CD, Vagh F, Hoard A, Gerstein N. Ultrasound-guided sciatic nerve block in the popliteal fossa using a lateral approach: onset time comparing separate tibial and common peroneal nerve injections versus injecting proximal to the bifurcation. Anesth Analg. 2010;110(2):635-637.

24. Dufour E, Quennesson P, Van Robais AL, et al. Combined ultrasound and neurostimulation guidance for popliteal sciatic nerve block: a prospective, randomized comparison with neurostimulation alone. Anesth Analg. 2008;106(5):1553-1558. [table of contents].

25. Prasad A, Perlas A, Ramlogan R, Brull R, Chan V. Ultrasound-guided popliteal block distal to sciatic nerve bifurcation shortens onset time: a prospective randomized double-blind study. Reg Anesth Pain Med. 2010;35(3):267-271.

26. Tran de QH, Dugani S, Pham K, Al-Shaafi A, Finlayson RJ. A randomized comparison between subepineural and conventional ultrasound-guided popliteal sciatic nerve block. Reg Anesth Pain Med. 2011;36(6):548-552.

27. Abdallah FW, Brull R. Making sense of block "success" in ambulatory anesthesia practice. Int Anesthesiol Clin. 2011;49(3):1-9.

28. Rancourt MP, Albert NT, Cote M, Letourneau DR, Bernard PM. Posterior tibial nerve sensory blockade duration prolonged by adding dexmedetomidine to ropivacaine. Anesth Analg. 2012;115(4) 958-962.
29. Bingham AE, Fu R, Horn JL, Abrahams MS. Continuous peripheral nerve block compared with single-injection peripheral nerve block: a systematic review and meta-analysis of randomized controlled trials. Reg Anesth Pain Med. 2012;37(6):583-594.

30. Marshall S, Tardif G, Ashworth N. Local corticosteroid injection for carpal tunnel syndrome. Cochrane Database Syst Rev. 2007;(2):CD001554.

31. Williams BA, Murinson BB, Grable BR, Orebaugh SL. Future considerations for pharmacologic adjuvants in single-injection peripheral nerve blocks for patients with diabetes mellitus. Reg Anesth Pain Med. 2009;34(5):445-457.

32. Williams BA, Hough KA, Tsui BY, Ibinson JW, Gold MS, Gebhart GF. Neurotoxicity of adjuvants used in perineural anesthesia and analgesia in comparison with ropivacaine. Reg Anesth Pain Med. 2011;36(3):225-230.

33. Ma R, Wang X, Lu C, et al. Dexamethasone attenuated bupivacaineinduced neuron injury in vitro through a threonine-serine protein kinase B-dependent mechanism. Neuroscience. 2010;167(2):329-342.

34. Tan PH, Liu K, Peng CH, Yang LC, Lin CR, Lu CY. The effect of dexamethasone on postoperative pain and emesis after intrathecal neostigmine. Anesth Analg. 2001;92(1):228-232.

35. Pasternak JJ, McGregor DG, Lanier WL. Effect of single-dose dexamethasone on blood glucose concentration in patients undergoing craniotomy. J Neurosurg Anesthesiol. 2004;16(2):122-125.

36. Shrestha BR, Maharjan SK, Shrestha S, et al. Comparative study between tramadol and dexamethasone as an admixture to bupivacaine in supraclavicular brachial plexus block. JNMA J Nepal Med Assoc. 2007;46(168):158-164.

37. Aasboe V, Raeder JC, Groegaard B. Betamethasone reduces postoperative pain and nausea after ambulatory surgery. Anesth Analg. 1998;87(2):319-323.

38. Nagelschmidt M, Fu ZX, Saad S, Dimmeler S, Neugebauer E. Preoperative high dose methylprednisolone improves patients outcome after abdominal surgery. Eur J Surg. 1999;165(10):971-978.

39. Bisgaard T, Klarskov B, Kehlet H, Rosenberg J. Preoperative dexamethasone improves surgical outcome after laparoscopic cholecystectomy: a randomized double-blind placebo-controlled trial. Ann Surg. 2003;238(5):651-660.

40. Wang PH, Tsai CL, Lee JS, Wu KC, Cheng KI, Jou IM. Effects of topical corticosteroids on the sciatic nerve: an experimental study to adduce the safety in treating carpal tunnel syndrome. J Hand Surg Eur Vol. 2011;36(3):236-243.

41. Shishido H, Kikuchi S, Heckman H, Myers RR. Dexamethasone decreases blood flow in normal nerves and dorsal root ganglia. Spine. 2002;27(6):581-586.

42. Brull R, Macfarlane AJ, Parrington SJ, Koshkin A, Chan VW. Is circumferential injection advantageous for ultrasound-guided popliteal sciatic nerve block?: a proof-of-concept study. Reg Anesth Pain Med. 2011;36(3):266-270.

43. McCormack K. The spinal actions of nonsteroidal anti-inflammatory drugs and the dissociation between their anti-inflammatory and analgesic effects. Drugs. 1994;47(Suppl 5):28-45; discussion 46-47.

44. Ahlgren SC, Wang JF, Levine JD. C-fiber mechanical stimulus-response functions are different in inflammatory versus neuropathic hyperalgesia in the rat. Neuroscience. 1997;76(1):285-290.

45. Barnes PJ. Anti-inflammatory actions of glucocorticoids: molecular mechanisms. Clin Sci (Lond). 1998;94(6):557-572.

46. McCartney CJ, Duggan E, Apatu E. Should we add clonidine to local anesthetic for peripheral nerve blockade? A qualitative systematic review of the literature. Reg Anesth Pain Med. 2007;32(4):330-338.

47. Eisenach JC, De Kock M, Klimscha W. Alpha(2)-adrenergic agonists for regional anesthesia. A clinical review of clonidine (1984-1995). Anesthesiology. 1996;85(3):655-674. 


\section{Publish your work in this journal}

Local and Regional Anesthesia is an international, peer-reviewed, open access journal publishing on the development, pharmacology, delivery and targeting and clinical use of local and regional anesthetics and analgesics. The journal welcomes submitted papers covering original research, basic science, clinical studies, reviews \& evaluations,

guidelines, expert opinion and commentary, case reports and extended reports. The manuscript management system is completely online and includes a very quick and fair peer-review system, which is all easy to use. Visit http://www.dovepress.com/testimonials.php to read real quotes from published authors.

Submit your manuscript here: http://www.dovepress.com/local-and-regional-anesthesia-journal 